\title{
Teaching reform and practice of Public Physical Education in Colleges \\ and Universities under the network environment
}

\author{
Senlin Lu \\ Jiangxi science \& technology Normal University Jiangxi Nanchang 330013
}

Key words: network environment; colleges and universities; public physical education; practice and thinking.

\begin{abstract}
: by using the method of documentary, logical analysis and other research methods, root of declining of colleges and Universities under the Network Environment College Students' physique and health status were analyzed objectively, public physical education teaching mode in Colleges and universities still remain within the confines of the past, can not solve the problems existing in the present stage. Must therefore be to increase research efforts, to integrate among colleges and universities sports resources, encourage the students to participate in sports activities of the positive enthusiasm, let happy sports has become the modern college students' favorite, optimize sports teaching evaluation system, to improve our country university students physique and health level of ascension to provide strong theoretical support.

Author introduction: Senlin Lu (1960 -), male, high Anren, Jiangxi science and technology Normal University, associate professor, research direction: sports training science teaching.
\end{abstract}

\section{One Analysis of the current situation of Public Physical Education in Colleges and Universities under the network environment}

With the rapid development of science and technology, especially the development of network technology, network has penetrated into all aspects of people's lives, and has a profound impact on the life of college students. Computer and mobile phone network terminal has become an indispensable important part of College students. The resulting static behavior of life is more and more serious, the development of the static behavior of life will cause adverse effects on college students, which must be highly valued by the university educators.

(One) The sports law of the people's Republic of China still needs to be revised

1995 in the national implementation of the "people's Republic of China Sports Law", the university must strictly implement the national physical training standards, to ensure that college students to participate in sports activities. According to the 2002 Chinese students' physical health monitoring results: college students overall morphological level increases, improve the nutritional status and common disease prevalence rate decreased; however, there are also problems such as unsatisfactory places such as college student obesity, overweight, decreased lung capacity and level of physical health is not ideal. The Chinese government has been very concerned about college students' physical fitness and health, developed a strict monitoring measures to fully grasp the physical and health problems of college students in China. The monitoring result is not ideal must be re adjustment or revision of College Students' physical exercise program, take more effective measures to deal with the ring network of College Students under the static life behavior lead to physical decline of practical problems. 


\section{（Two） Existing defects of the current students' physical health standard}

Facing the existing in the network environment of university students physical and health problems, to strengthen the physical education in Colleges and universities, improving university students' physical quality and health level, the State Sports General Administration and the Ministry of education to organize experts to carry out extensive and in-depth investigation and research, on the basis of a large number of first-hand information in the revised and perfected the "Student Physique Healthy Standard" and executed in the country to promote.

However, after a period of practical use, it is found that the phenomenon of physical and health decline caused by the static behavior of college students in the network environment is not much effect. After a careful analysis of the revised "student's physical health standard (Trial Scheme)" after the discovery did not really combined with the actual school students to put forward a targeted modification measures. Some items score standard is too low is not conducive to the improvement of the effectiveness of school sports work, the designated training programs and content change is not, the threshold is too low can not really motivate students to participate in sports enthusiasm. Standard is too low relative weakening of the physical education in Colleges and universities, has no great influence on the improvement of College Students' physical fitness and health; due to the revised "Student Physique Health Standard (trial version)" on the school physical education teaching content there is no clear requirements, in the implementation process is difficult to control will eventually weaken the school sports work to influence student's physique and the health standard, enhance.

(Three) The teaching mode of Public Physical Education in Colleges and universities needs to be reformed

Our country followed years of college public physical education teaching mode, up to now, there is no fundamental change, promulgated by the state sports qualified standard guiding the student physical health standard (trial version) "has not too big change, and has a direct impact on the reform and development of public sports teaching in Colleges and Universities. With the rapid development of science and technology, college students living and learning environment occurred earth shaking changes, especially the development of network technology, network terminal computers and mobile phones have been popular, college students to participate in sports activity is greatly reduced, to take active part in physical exercise activities greatly weakened, use their phones to access the Internet, check the information, finding information, play QQ, play micro channel and watching movies has become the main living mode of the college students' learning, Bow Group, such as static life crowd behavior is expanding, traditional teaching mode of public physical education has been far from solving the above problems, the public physical education teaching mode in Colleges and universities in need of reform.

\section{Two Vxploration on teaching reform of Public Physical Education in Colleges and Universities}

\section{(One) The teaching of Public Physical Education in Colleges and universities is facing new challenges}

Enhancing college students' physical fitness and promoting the healthy growth of college students are related to the future of the nation and the nation. In the face of the fact that college students' physical health is declining, the popularity and influence of modern network technology is the direct cause, but the teaching of Public Physical Education in Colleges and universities is not a very important factor. College public physical education has its own characteristics, to evaluate the teaching effect is consistent with the needs of College Students' physical fitness and health 
promotion, the monitoring, evaluation, evaluation system design is reasonable, whether smoothly obtain accurate reflect students' physique and health monitoring according to the crucial, because only ready access to reflect the students' physique and health of specific data to timely to the teaching effect of effective monitoring.

Public physical education teaching mode in Colleges and universities how to adapt to the realistic need of promoting students' physique and health under the network environment, how to set up good students' physique and health status data collection system and the monitoring system is to solve the problem. Through extensive investigation and research, in accordance with the full and repeated demonstration of the development of practical teaching mode of Public Physical Education in Colleges and universities. The formation of the vigorous development of public sports teaching in Colleges and universities, by attracting the whole society, family members and students actively participate in the purpose of physical exercise.

\section{(Two) The transformation of physical education teaching mode}

College public physical education teaching has always been to enhance college students' physical fitness and health as a teaching goal. With the changes of the times and the environment, students' physical health standard requirements of the standard and test content should be changed, related to the various aspects of the students' physical quality improvement. Despite the tremendous changes have taken place in modern science and technology, social, political and economic, but the development of College Physical Education Reform in China never really had jumped the existing frame. That led to the current decline of College Students' physical fitness in today's reality. Therefore to completely change the current situation, the small trouble didn't play much of a role, but to completely transform the university public physical education teaching mode, allow more advanced public sports teaching mode instead of the current has already been no longer suitable for the current students of public physical teaching mode.

(Three) College public physical education should focus on the cultivation of interest in physical exercise

To completely change the current is not suitable for college students in public sports teaching mode, should be focused on guiding college students to develop an active participation in the general interest in physical exercise. Because only interested in order to produce efficiency, in order to stimulate the enthusiasm of college students to participate in sports activities. College students to participate in sports activities in also with the environment, time and community needs change, in addition to their own needs, the external force but also can promote students to participate in sports activities in Colleges and universities need to create a desire to let all the teachers and students of physical fitness exercise exercise sports atmosphere, to learn knowledge skills at the same time enhance training. Cultivate indomitable physical quality excellent quality as the ultimate goal of teaching under the premise of ensuring safety, no matter what kind of public sports teaching mode as long as it can fundamentally change the current teaching mode of college students to participate in sports activities, poor effect should promote, let University public sports teaching full of vitality, but the effect is not seeking to make process. In this active sports spirit filled in every corner of the campus.

(Four) Innovation and breakthrough of the teaching mode of College Public Physical

\section{Education}

Countries in the formulation of new national student physical health standard test, must jump out of the original restrictions and fetters. To fully embody a spirit, that is the spirit of sports. Can not always be in the project test and project content to adjust, but to teach students how to understand and carry out the implementation, and ultimately achieve the goal of the reform of sports 
spirit. However, public colleges and universities sports teaching teachers to reduce the difficulty and frequency of sports activities of college students, also appeared frequently bad phenomenon of laissez faire style of free activities for college public physical education class teaching, lead to physical education in public colleges and universities did not reach the expected effect. The reform of public physical education teaching mode is to realize the change of teaching mode, which is based on the teaching mode of sports free style, to strengthen the teaching mode. If the university public sports classroom teaching mode does not carry on the breakthrough reform, still continues the original teaching mode, the university student physique decline tendency is very difficult to the fundamental transformation. College Public Physical Education Teaching and research staff, to the public PE teaching reform as a top priority task, actively explore the root of happiness of College Students Sports feeling, formulate corresponding teaching mode of public physical education to guide the students happy participation to enhance physical fitness of the ultimate goal. College public physical education class teaching management departments to countries formulate new the national student physical health standard "provides the high quality material, through scientific and reasonable" national student physical health standard "to promote public physical education teaching mode in Colleges and universities is more reform and scientific innovation and breakthrough.

\section{(Five) The sharing of teaching resources in College Public Physical Education}

As is known to all, public colleges and universities sports content multiple parallel modules, such as regular college public physical education curriculum, student mass organizations of sports events, the all levels of sports activities, college students choose the physical exercise program. Conventional physical education curriculum is mainly the design by the talent cultivation, his application for the student mass organizations, to organize their own, manage their own sports activities in the group responsible person or entrusted the leadership of the teachers run, often show the old with the new, high level lead low water inequality, and the existence of teachers always spot guidance factors; college students between a variety of sport is the sports highlights, runs through the whole process of college students in the school life is mass sports activities in Colleges and universities. The high level sports teams of all kinds of projects are the catalysts for the activation of the university sports. So, how will the sports module organic fusion to form a unique campus sports culture in Colleges and universities, is a strong sports atmosphere of the adhesive, is all colleges and Universities between establish an effective platform for the exchange of sports culture.

\section{(Six)Optimization of teaching quality evaluation system of Public Physical Education in Colleges and Universities}

To truly improve college students' physical fitness and health level, to achieve an accurate determination of College Students' physical and health status, the establishment of public sports teaching evaluation system is essential. It is not only an important part of college public physical education, but also the monitoring and testing method of physical education teaching achievement. In order to grasp the information of the various links in the teaching of public physical education, the evaluation system should be used to measure the quality of public sports teaching and to ensure the regulation and control of the quality of the teaching. Including teaching contents, organization, methods and means, teaching attitudes and students class attitude, ability to accept, the effect of exercise, so that teachers and students can communicate at any time, will eventually be able to smooth reform and achieve the desired effect; from the point of view of the teaching achievement, to a proper test standard test students' physique, physical fitness and health status. Of PE teaching evaluation system is established to closely focus on the students' physique and health as the core, to promote college students' in addition to the normal public PE classroom teaching more to actively 
participate in various forms and levels of sports.

\section{Three、Summary}

Faced with the situation of College Students' physical fitness and health in our country, how to innovate the teaching of Public Physical Education in Colleges and universities, how to achieve the goal of improving college students' physical fitness and health status. College Public Physical Education Teaching and research staff to increase of College Students under the network environment, static behavior of living behave more and more serious situation of, and actively explore teaching mode innovation, for the establishment of the National Book New the student physique health standard "to provide theoretical support, integration between college sports resources, encourage the students to participate in sports activities of the positive enthusiasm. Let happy sports become the most love of modern college students. According to the reality of the emergence of college students in the network environment to actively optimize the evaluation system of physical education, in order to enhance the level of physical fitness and health of college students to provide strong support.

\section{Reference:}

Zhang Jian. From the point of view of the essence of Physical Education Sports Teaching (J). Sports and science, 2008 (3).

2 section Jianzhi. Problems of college physical education curriculum reform analysis J. Journal of physical education, 2006 (3).

Fan Xiaowei, Liao Benlu, Wu Zhenchao. The health standard of students' Constitution (Trial Program) and the reform of physical education curriculum in Colleges and universities (J). Educational exploration 2008 (4).

4 Party Wei Xi, Zhang Xuezhong. A new round of physical education curriculum reform -- the ideal and the reality of the opposition J. Journal of physical education, 2010 (10).

[5] huangmin, Chen Yingjun, Li Yali. Human nature from the perspective of the reform of physical education in Colleges and universities present situation and prospect [J]. Journal of physical education, 2011 (5). 